\title{
El Plan Carter y "La Guerra de la Energía"
}

UN PRESIDENTE DEMOCRÁTICO QUUE CUMIPIE SUS PROMESAS ELECTORATES Y NO THME SER IMPOPUIAR

Se ha señalado repeticlamente en los últimos tiempos que uno de los graves defectos del sistema democrático consiste en que las promesis hechas durante las campañas electorales no se cumplen cuando Ios candidatos llegan al poder y que para mantenerse en el gobierno, los politicos deben halagar continuamente a las masas, a fin de asegurar la preeminencia de su partido y su propia reelección. En una palabra, el sistema democrático se basa en la demagogia, y la clemagogia eś lesiva para el interés nacional.

El presidente de la democracia más poderosa clel mundo acaba de dar un rotundo mentís a los críticos del sistema clemocrático al dirigirsc al pueblo y al Congreso norteamericanos ci ls y 20 de abril pro. poniendo Ia adopción de un plan de energia para los Istacios Unidos que, sigún sus propias estimaciones y' la de los expertos en publicidad, haria bajar su populariclad en aproximadamente un $15 \%$, una reducción casi dramática para un presidente que lleva sólo cien días en el gobierno.

En el primer debate televisado Forcl-Carter, el actual presidente abogó por la unificación de los múltiples organismos del Gobierno Federal con respecto a la energía, sosteniendo que la actual organización conducía al despilfarro de dinero, a la duplicación de funciones y a la ineficiencia burocrática, y anunció su plan de energía, esbozando algunas de sus icleas matrices.

Poco después de asumir la presidencia, se fijó a sí mismo el 20 de abril como plazo fatal para presentar un plan energético y asi lo anunció al pais. Su primera tarea era nombrar al hombre aclecuado para encarar esta gigantesca empresa en la cual habían fracasado anteriormente Richard Nixon y Gerald Ford. Tras una angustiosa búsqueda, su elección recayó en James Rodncy Schlesinger, de 48 años, doctor en Harvard summa cum laude, un brillante intelectual especializario en el análisis de sistemas, que ocupó sucesivamente los 
Cargos de Director de la Comisión de Energía Alómica, Director de la CIA y Secretario de Defensa, y que goza de amplio prestigio en la.naCión. Bajo Ias directivas de Carter, Schlesinger recibió instrucciones de claborar el plan en tres meses y cumplió su mandáto. Los seclores económicos de Carter, Blumenthal, Secretario clel Tesoro, y Schultze, Jefe clel Equipo de expertos en cconomía, pidieron más tiempo para se dirigió a la nación explicando los fundamentos y el contenido de estudiar el plan, pero Carter se negó a ello y el lunes is de abril se dirigió a la nación explicando los fundamentos y el contenido de s.u programa. Dos días más tarde, el Presidente, ante una sesión conjunta del Congreso, leía su mensaje, proponiendo el plan energético. al Congreso, nó es un hecho accidental: cnvuelve una estrategia cici Esta explicación del plan en dos tiempos, primero a la nación y luego al Congreso, no es un hecho accidental: envuelve una estrategia del Presidente en la gran batalla para obtener su aprobación, a la cua? nos referiremos màs adelante.

En el activismo de Carter y su sentido de extrema urgencia para la elaboración y lanzamiento del plan, jugó un papel importante, como factor catalítico, un informe secreto de la CrA sobre los recursọs, mundiales de petróleo, informe lque, por orden de la Casa Blanca, se hizo de conocimiento público el 19 de abril. En este. estudio, la CLA pronostica que, de mantenerse las tasas actuales de consumo, las clemandas mundiales de petrólco sobrepasarán a lia oferta a mediados de la década de 1980, causando graves trastornos económicos. El hecho clave al respecto consiste en que la Unión Sovićtica, que ahora es un exportaclor neto de petrólco y que suple a sus aliados de Europa Oriental, clejará de serlo hacia 1985, transformándose en importador. Estados Unidos y la URSS tendrán que empezar a competir, entonces, por el petróleo del Medio Oriente y de los clemás praises de la OPEP, con la consiguiente agravación de las tensiones políticas en esa zona y'a tan conflictiva del mundor. Es fácil imaginar que sucederia en esa época, desde el punto cle vista político. económico cuanclo las dos superpotencias tengan. que abastecerse de las mismas fuentes del precioso combustible. Dos escenarios podrian perfilarse: uno de confrontación, en el cual las tensiones podrian :llegar a su límite más extremo; el otro de entendimiento, en el cual las dos superpotencias podrian crear un "proteclor"ado" en el Medio Oriente, para asegurarse "equitativamente" sus abastecimientos. No hay que olvidar a este respecto que lo que ha impedido hasta ahora una intervención militar de Estados Uniclos en el Medio Oriente es el peligro de que tal intervenxión pudiera llevar a una gueria nuclear con la Unión Soviética. Pero si la URSS también necesitara

1 Time, May. 9, 1997. pp. 34-36; The-Economist; 28-29, April; 1977, p. 81. 
hacia 1985 importar petróleo, tal peligro desaparecería en el escenario del "entendimiento" y podría surgir el "protectorado" respaldado por ambos gigantes, lo cual, entre otros efectos, significara también el fin de la OPEP.

Por una curiosa coincidencia fuc el propio Schlesinger, entonces Secretario de Defensa de Ford, el que desmintió la posibilidad de intervención militar en el Medio Oriente a raiz del embargo petrolero y de las amenazas "veladas" de Ford de recurrir a la fuerza."

Si Carter fuera reelegido para un segundo periodo, le tocaría asistir a la gestación de la crisis a principios de los $80 \mathrm{y}$ enfrentarse al conflicto y'a desencadenado al término de su último mandato.

LOS ESTADOS UNIDOS: UNA ECONOMIA BASADA

EN EL DESECHO DE ENERGIA

Es curioso observar, en el campo de las Ciencias Sociales, que, a veces, un ensayista intuitivo o un político, se adelantan a los académicos rigurosos y científicos, en la percepción y pronóstico de algunos fenómenos de la sociedad. El 19 de febrero de 1939, el Presidente Franklin D. Roosevelt declaraba: "Nuestros recursos energéticos no son inagotables y sin embargo, nosotros los derrochamos"'. Pocos meses más tarde estallaba la Segunda 'Guerra Mundial y quizás por ello, Roosevelt, requerido por las apremiantes exigencias del conflicto no pudo traducir en la práctica su diagnóstico sobre la energía.

Mucho antes de que naciera la futurologia, un ensayista, Vance Packard, famoso ya por su libros, "The status seekers" (los buscadores de status) y "The hidden persuaders" (sobre la industria de la propaganda comercial para aumentar el consumo superfluo), pupublicada en 1963 su libro "The Wraste Makers" (Los fabricantes de desecho o Ios despilfarradores) en el cual criticaba acerbamente el estilo norteamericano basado en el consumo por el consumo, señalando que este nuevo Mammon amenazaba el futuro de los norteamericanos como individuos y como nación. La filosofía del libro era clara: "Una sociedad en la cual ch consumo tiene que ser artificialmente estimulado para que la economia pueda seguir funcio-

- Gustaro Lagos, El petróleo: La nueva Revolución de Octubre, en Gustaro Lagos, La détente y las crisis planctarias" (Santiago, Chilc: Seric de publicaciones especiales No 16 del Instituto de Estudios Internacionales de la Universidad de Chile, 1956), pP: 203-214.

3 Le Monde, Selection hebdo madaire, 21.27 avril, 1977, p. 2. 
nando, es una sociedad fundada en la basura y el. despilfarro y:una sociedad semejante es una casa construida sobre la arena"."

Una sociedad de consumo es por esencia una sociedad de alto consumo de energía, ya que, en último término, toda la economía requiere combustible. Proféticamente, Vance Packard consagraba en consecuencia, un capitulo de su libro a los recursos naturales, titulándolo "los recursos que se desvanecen.". En él escribia: "La dependencia de Ios Estados Unidos de fuentes externas tiende a rrecel: con cada década que pasa a una tasa riolentamente creciente si la población y los hábitos de consumo individuales de sus ciudadanos crecen tan bruscamente como la propaganda comercial espera que suceda". Refiriéndose específicamente a la energia señalaba que el consumo de petróleo, la principal fuente energética del pais, habia triplicado desde el fin de la Segunda Guerra Mundial, que la nación sólo poseía un séptimo de las reservas probables de petróleo, mientras que consumía más de la mitad de la producción mundial ${ }^{6}$. Anunciaba, asimismo, que la supremacia del pais como productor de petróleo se acercabay a su fin y que en el futuro los Estados Unidos dependerian más y más de fuentes extranjeras y "ello lo está entr.cgando profundamente en las manos de los políticos árabes y latinoamericanos" (se refiare a! petróleo de Venezuela, tradicional abastccedor de Ios EE.UU.) .

Estas sombrias predicciones, actualizadas por el informe de la CIA, se encuentian en el trasfondo del plan de Carter.

En sus discursos del is y 20 de abril, en tono sobrio, a veces dramático, el Presidente, con su dejo de acento sureño, planteó lá alternativa: o Estados Unidos adopta el plan energético del gobierno o se enfrenta a una catástrofe nacional: "El mundo no se ha preparado para el futuro. Durante la década de 1950 se consumió el doble de petróleo que se usó en la década de 1940, durante la clécadá de 1960 empleamos el doble de lo que usamos en la década de 1950. $Y$ en cada una de esas décaclas, se consumió más pecróleo de lo que se había consumido en la historia previa de la humanidad. El consumo mundial de petrólco sigue aumentando. Si durante las décadas

+ Dorothy L. Saycrs en Creed or chaos, citado por Vance Packard, "The Waste makers (Nert York, Simon and Schuster, 1963).

5 Vance Packard, ibid, p. 172,

E Ibid, p. 174. Para formular este diagnóstico $y$ su visión profética, Vance Packard se basó en estudios de diversos autores; entre ellos, cabe citar la obra de F. Osborn Los limites de la tierra (México - Buenos Aires, Fondo de Cultura Económica, 1956); como la edición americana es de 1953, Osborn, en algunos aspectos, se adelantó casi dos décadas a Los limites del Crecimiento del Club de Roma. Sin embargo, creemos que la profecia de Packard sobre la futura dependencia de Estados Unidos con respecto al petróleo árabe y v'cnezolano, es absolutamente suýa en cuanto a su originalidad. 
dé 1970 y 1980 fuera posible mantener el actual ritmo de aumento anual de un cinco por ciento como en el pásado, para fines de lá prơxfina década habríamos utilizado todas las reservas de petróleo conocidas en el mundo "Gada norteamericano utiliza el equivalenté de 60 barriles de petróleo por persona al año. Nuestra nación ís la más demrochadora clel mundo. Desperdiciamos más energia de la que importamos. Con el mismo nivel de vida, usamos el doble de enèrgia de lo que otra persona emplea en países como Alemania, Japón y Suecia...". "A menos que actuemos, para 1985 gastaremos más de 550.000 millones de dólares (aproximadamente el P.N.B. del Japónin) en importar petróleo -más de 2.500 clólares por cada hombre, mujèr o niño en los Estados Unidos. Junto con ese gasto de dinero, seguiremos perdiendo empleos y rolviéndonos más vulnerables a las in.terrupciones del abasteciminto. Hoy tenemos una opción. Pero si esperamos, viviremos con el temor de los embargos. Podemos prepararnos ahora mismo. Podemos decidirnos a actuar mientras haya tiemipo".

Tal es el propósito del Plan Nacional cle Energía.

LOS DIEZ PRINCIPIOS DEL PLAN:

EL AHORRO DE ENERGÍA COMO VIGA MAESTRA

En apretado resumen, los diez principios del PIan son los siguientes: 1) el plan sólo puede ser efectivo si el Gobierno asume la responsabilidad del mismo y el pueblo comprende la gxavedad de la situación y. está dispuesta a hacer sacrificios; 2) clebe continuar un saluclable crecimiento económico que permita mantener el nivel cle vida y conservar a la gente en su trabajo; 3) debe protegerse el medio ambiente ya que la contaminación tiene el mismo origen. que el problema energético: el despilfarro de recursos; 4) debe reducirse la vulnerabilidad del pais con respecto a embargos potencialmente devastadores. Para ello debe disminuirse la demanda de petróleo, deben aprovecharse al máximo los recursos abundantes de carbón de la nación y desarrollar una reserva estratégica de petróleo; 5) el Plan debe serequitativo, demandando iguales sacrificios de cada región del pais,

T Tex̣to oficial del discurso del Presidente Carter ante la nación sobre la crisis de energfa, pronunciado el 18 de abril, Servicio ce Cultura y Prensa de la Embajada de EE.UU., Santiago, abril 20,197\%. Todas las citas que aparecen en este artículo cutre comillas sin mención específica de fuente cstán tomadas de cste texto o de la versión, tambićn oficial, del discurso del Presidente ante el Congreso, proporcionada por el mismo servicio de Ia Embajada.

8 Nota del Autor. 
de cada clase de personas, de cada grupo interesado. La industria debe ahorrar al igual que los individuos. Los productores de energía recibirán un trato justo pero el Gobierno no permitirá las especulaciones de las compañias petroleras; 6) el fundamento principal del Plan es reducir la clemanda por medio del ahorro. Ello lo diferencia dc planes anteriores (el Proyecto Independencia de Nixon y el Proyecto de Ford) que ponian el énfasis en la producción.". El ahorro es la fuente de energia más jápicla, más barata y más práctica. El ahoro es la única forma de comprar un bartil de petróleo por unos pocos clólares. Cuesta unos 13 dólares clespercliciarlo"; 7) los precios deben reflejar generalmente el costo verdadero de reponer lá cnergía. Un precio cle la energía arficialmente barato sería un engaño y aumentaria el consumo más allá cle lo que el pais puede permilirse; S) las normas que cstablexca el Gobierno deben ser prerisibles y' seguras con el objeto de que procluctores y consumidores de energía puedan planificar de antemano. Para ello el Gobierno propondrá al Congreso la creación cle un Departamento de Energia que reemplace a más de 50 agencias que ahora tienen competencia en la maleria; 9) el país debe ahorrar los combustibles que están más escasos y usar aquellos que abundan. Es decir, la nación debe ahorrar petróleo y gas natural, que constituyen el $7 \%$ de las reservas nacionales y que, sin cmbargo, representan actualmente el $75 \%$ del consumo; debe utilizar, en cambio, el carbón que existe en abundancia (tomando las medidas adecuaclas para impedir la contaminación). En cuanto a la energía nuclear, hay que aplicar normas más estrictas de seguridad; 10) el país debe comenzar a desarrollar ahora las nuevas fuentes no convencionales de energía de las que clepenclerá el próximo siglo.

Estos dicz principios se traducen en diversas medidas específicas.

\section{"EL EQUIYALENTE MORAL DE UNA GUERRA"}

Así calificó el Presiclente Carter el alcance y' significación del Plan Energético en su Mensaje al Congreso. Señaló igualmente que la realización de su proga ania exigía la movilización total del pueblo norteamericano y' cle sus gobernantes en el "equivalente moral de una guel'a" que "clemandaría lo mejor de nosotros - nuestra visión, nuestra dedicación, nuestro valor y nuestro sentido de un objetivo común".

Ante los legisladores, Carter insistió en que su plan es un todo coherente, "un programa cuidadosamente cquilibrado, cuya ecuanimidad depende che todas sus principales partes componentes". 
No hay que olvidar que su autor, Schlesinger, pertenece al reducido club de especialistas en análisis de sistemas y que el propio Carter es ingeniero. En resumen, el plan es un sistema integrado por un conjunto de medidas que se refieren al ahorro de energia, pilar del programa, a la producción, a la conversión (especialnente al carbón), al desarrollo científico y tecnológico en materia energética $y^{\prime}$ a la repartición equitativa de las cargas $\mathrm{y}^{\prime}$ beneficios que el programa implica.

Desde el punto de vista de las doctrinas o teorias económicas, el plan representa una via media entre el simple juego de los mecanismos del mercado, caracteristicos del liberalismo y' una solución más radical que significaría controles y medidas autoritarias del Gobierno Federal. 9

Es el pueblo, a través de su gobierno, el que fija la política energética, el que asume la responsabilidad de su realización, estableciericlo "normas previsibles y seguras" en los aspectos indicados más arriba, es el Gobierno el que asegura el cumplimiento de las metas establecidas "por medio de la cooperación voluntaria y con un mínimo de coacción", brindando estímulos finarcieros, pero también imponiendo "sanciones y restricciones".

El Gobiemo establecerá "un. sistema independiente de informàción con respecto a las grandes empresas", que le proporcione "datos dignos de confianza' respecto a nuestras reservas y' producción cle energia, a nuestra capacidad para hacer frente a las emergencias y' a' los aspectos financieros de los productores de energía".

En una referencia directa a las grandes corporaciones transnacionales del petróleo, el Presidente recomienda al Congreso "que se exija una contabilidad individual a las empresas de energía para la produción, refinamiento, distribución y comercialización, en forma separada para los operaciones nacionales y extranjeras. La estricta aplicación de las leyes antimonopolios pueden basarse en esta información y puede que prevenga la necesidad de recurrir al desposeimiento".

Dominará finalmente aquel que esté mejor informado", escribió Benjamin Disraeli. Es el principio en que se basará el Gobierno Federal para impedir que las corporaciones transnacionales obtengan "grandes' beneficios injustamente ganados" y puedan manipular datos e informaciones que afectan a toda la nación y muchas veces al mundo. Toda la política del Gobiemo Federal deberá estar dirigida por una nueva secretaria de Energia cuya creación se recomiencla con urgencia al Congreso.

9 Ye Monde, ibid. 
El sistena de estímulos, sanciones y restricciones esbozado anteriormente descansa en el principio de recompensar económicamente a los que economizan energia y sancionar a aquellos que la derrochan.

Tal sistema exige un diagnóstico preciso de las causas del despilfarro y Carter lo establece en su Mensaje al Congreso, diseñando con respecto a cada causa medidas especificas del plan.

Las causas del derroche derivan de cuatro sectores: el sistema de transportes, los sistemas de calefacción y aire acondicionado, en las viviendas y edificios, los aparatos electrodomésticos y el sistema, de tarifas de los serricios públicos. En los dos primeros se concentrá el mayor despilfarro de energía.

DIAGNÓSTICO Y MEOIDAS EN EL SISTEMA DE TRANSPORTES

El transporte consume el $26 \%$ de la energía y un $50 \%$ puede considerarse dilapidada. Por tanto el ahorro en este solo sector, en el supuesto óptimo, podría economizar el $13 \%$ de toda la energia gastada por el país. Las medidas diseñadas tocan un aspecto fundamental del estilo de vida norteamericano: el uso de grandes automóviles que en promedio pesan 4.100 libras, mientras que en Europa el promedio es cle 2.700 libras.

En Estados Unidos "los tres cuartos de los automóviles llevan a una sola persona -el conductor - mientras que el sistema de transporte público, pierde el $50 \%$ de su energía sin haber sido utilizada". Hay un lujo de los grandes espacios perdidos con la consiguiente sobrecarga del tráfico de las calles, de las ciudades y de las autopistas y del consumo de gasolina.

El Congreso ya ha aprobado normas sobre eficiencia que obligan a los nuevos automóviles a rendir 44 kilómetros por galón para 1985 , en lugar de los 29 que son el promedio actual, para garantitan que se cumplan estas normas, Carter propone un impuesto gradual sobre Jos nuevos vehículos que violen estas disposiciones, impuesto que comenzará en un nivel bajo (en 1978, 180 dólares o 450 dólares para aquellos que rindan $24 \delta 17 \mathrm{Kms}$. por galón respectivamente) que se irá elevando hasta llegar a 1.600 y 2.500 dólares de 1985. P.or 
otra parte, todo el dincro recaudado por este impuesto será devuelto a los consumidores por medio de reembolsos en los casos de automóviles qué sean más eficientes que el mínimo requerido.

Además de este impuesto, el plan propone un impuesto a la gasolina y normas para aumentar Ia eliciencia clel sistema de carreteras $y^{\prime}$ autopistas. El impuesto sobre la gasolina constituye uno de los aspéctos más controvertidos del plan, y consiste en una tributación adicional de 5 centavos de dólar por galón que automáticamente se poridliá en vigor cada año en que no se alcancen las metas fijadas. Si un año no se cumple el objetivo, pero se logra el año siguiente, el impuesto adicional clesapareceria. Al igual que en el caso de los autómóviles gastadores de gasolina, el impuesto será retornado al pueblo en forma equitativa.

Por último, como los gobiernos estatales recaudarán menos dinero debiclo al impuesto fecleral sobre la gasolina, para superar esta dificultacl y asegurar un adecuado mantenimiento de carreteras ${ }^{\circ}$ ' autopistas, el Plan compensará a los Estados por esta pérdida a través de un fonclo fiduciario de carreteras.

\section{DERROCHE EN SISTENIAS DE CALEFACCIÓN Y AIRE ACONDICIONADO} EN VIVIENDAS Y EDIFICIOS Y MEDIDAS PARA CONTRARRESTARLO

El Piesidente diagnostica que este es el segundo campo iniportante en que se dispilfarra la energia, que en algunos casos llega al $50 \%$ de la energia utilizada en calefacción y aire acondicionado.

Para impedir la dilapidación, el plan propone una serie de medidas entre las que cabe destacar las siguientes: 1) el ejemplo del Gobierno Federal en sus propios edificios, para lo cual Carter expedirá una orden ejecutiva estableciendo estrictos porcentajes de ahorro energético; 2) normas en los sistemas de calefacción y enfriamiento de los nuevos edificios, públicos y' privados, y reacondicionamiento de los antiguos para producir drásticas reducciones del combústible utilizado a través de técnicas de aislamiento térmico y otras medidas; 3) deducciones tributarias para los propietarios de vivienclas que hagan mejoras destinadas al ahorro de energia, que pueden fluctuar entre el $25 \%$ en los primeros 800 dólares invertidos y un $15 \%$ en los 1.400 dólares siguientes; 4) se exigirá a las empresas de servicios de gas y alumbrado que proporcionen sistemas de aconclicionamiento de la temperatura en las viviendas que concedan financiamiento en términos razonables a los propietarios que éstos 
pagarán a través de pequerios incrementos regulares en su cuenta mensual; 5) ayuda federal a los residentes de bajos ingresos; 6) fondos de obras públicas para acondicionamiento de temperatura en los edificios de los gobiernos locales y' estatales.

\title{
APARATOS ELECTRODOMÉSTICOS
}

Se propone una legislación que, por primera vez, impondrá medidas de eficiencia a las fábricas de aparatos electrodomésticos para 1980, destinadas a ahorrar energia.

\author{
SISTEMAS DE TARIFAS DE SERVICIOS PÚBLICOS: \\ W AUTORIDAD DEL VALLE DE TENNESSEE COMO MODELO
}

Estados Unidos seguirá el ejemplo de Alemania en. proyectos de cogeneración. El Plan propone medidas legislativas que requerirán la adopción de una serie de disposiciones en los próximos dos años: 1) las compañias productoras de clectriciclad y gas natural deberán eliminar gradualmente las tasas de promoción y los precios artificialmente más baratos para los consumidores de gran volumen y' deberán ofrecer a los usuarios precios mús alros durante el día cuando la demanda es mayor y' más bajos durante las horas en que la demanda es pequeña; 2) se establecerán medidores individuales para cada departamento en los nuevos edificios en lugar cle un medidor centrai.

Para que las propias autoridades den el ejemplo en el cumplimiento de las medidas anteriores, el gran complejo del Valle de Tennesse actuará como modelo en la implementación de estas normas.

Por último, se concederá una deducción tributaria de un $10 \%$ para las inversiones destinadas a los proyectos de cogeneración que consisten en sistemas que ahorran gran parte del rapor actualmente desperdiciado en la generaqión de electricidad. En esta materia, el programa de Carter sigue el ejemplo de Alemania Federal en la cual el $29 \%$ del total de la energía proviene de la cogeneración mientras que en Estados Unidos este porcentaje alcanza sólo al $4 \%$.

Las grandes metas en materia de producción energética: Estados Unidos renuncia a la autosuficiencia en petróleo y gas natural $y$ crea 
una rescrva estratégica de petróleo para prevenir un nuevo embargo de la OPEP.

Las medidas del Plan parten de una constatación esencial: Éstados Uniclos jamás podrá incrementar su producción de petróleo y gas natural en forma suficiente como para satisfacer su demanda.

Carter propone en consecuencia tres metas en este campo: asegurar un sistema de precios razonables para los productores de energía, desalentar el despilfarro $y$ alentar la exploración y la nueva producción, pero sin dar a los productores mayores beneficios que los que realmente necesitan para realizan estos objetivos. Carter considera que las propuestas para la eliminación inmediata y total del control de los precios del petróleo y del gas natural nacionales seria desastrosa para la economía y para el trabajador norteamericano y' no resolvería los problemas a largo plazo de las reservas finitas del país. En cambio propone que los precios de la energia reflejen su verdadero costo de reposición $y$ que los precios 'del petróleo recientemente descubierto aumenten en un período de tres años hasta alcanzar los niveles del mercado mundial, dejando margen de compensación para la inflación. En contraste, el precio del petróleo previamente descubierto continuaría sin variaciones, excepto el ajuste necesario debido a la inflación. Para ello se establecerá un impuesto según la fuente de origen de petróleo nacional igual a la diferencia entre el precio actual controlado del petróleo y el precio mundial, devolviendo el dinero así recaudado por el Gobierno a los consumidores y trabajadores.

Para prevenir la eventualidad de posibles futuros embargos provenientes de la OPEP, el Plan propone la creación. de una reserva estratégica de petróleo de Estados Unidos, de 1.000 millones de barri$l_{e s,}$ equivalente al abastecimiento para poco más de seis meses.

"Estados Unidos no debe permitir que la carestía energética lo convierta en otra región balcánica".

Con esta expresión destacada en su mersaje al Congreso, Carter aborda los problemas relativos a la política de producción y' precios con respecto al gas natural dentro del Plan. Propone terminar con las distorsiones artificiales del precio de este combustible, que han creado carestías, desempleo, y estancamiento económico, particularmente en el Noreste; propicia dar a los productores de gas un incencivo suficiente para la exploración de nuevas fuentes, elaborando uná polílica destinada a liberar la regulación del gas natural nuevo a medida que las condiciones del mercado lo permitan. Como medida inmediata propone que el limale del precio para todo gas nuevo se fije al precio equivalente en valor energético al del petróleo crudo nacional a parting de 1978 . 
"Nacimos en la era clel petróleo y del gas natural: es preciso retor. nar al carbón cuando fuere posible".

La primera revolución industrial, originada como es bien sabido, en Inglaterra, se basó desde el punto de vista energético, en el paso de la madera, que proporcionaba el $90 \%$ de todo el combustible, al carbón, que tenía una mayor eficiencia. Como lo señalara Carter en su discurso a la nación, "el segundo cambio ocurrió este siglo, con el creciente uso del petróleo y del gas natural. Eran más convenientes y menos costosos que el carbón y el suministro parecia ilimitado. El petróleo y el gas hicieron posible la era de los viajes en automóvil y en avión. Casi toda la gente que está viva hoy creció durante esa era y' no hemos conocido nada diferente".

Ahora ante el agotamiento de las reservas de gas y petróleo, es preciso impedir que estos combustibles sean desperdiciados por las industrias y plantas eléctricas que pudieran usar carbón en su lugar. Por tanto, hay que retornar al carbón, que es abundante en los Estados Unidos, cuando ello sea posible. El carbón constituye el $90 \%$ de las reservas energéticas del país y tan sólo provee el $18 \%$ de consumo energético nacional. Si bien es cierto que su producción y uso crean contaminación, es preciso remediar estos inconvenientes "por me. dio de estrictas normas para la mineria de superficie y conservación del aire puro". El desarrollo de nuevas tecnologias para la explotación y uso del carbón está destinado a proporcionar un alto rendimiento y está al alcance del país que ha gastado hasta ahora miles de millones de dólares en la investigación y desarrollo de la energía nuclear y, en cambio, muy poco con respecto al carbón.

La meta del plan es aumentar el uso del carbón en 400 millones de toncladas, o sea, un $65 \%$ en la inclustria y plantas eléctricas para 19S5, para lo cual el Presidente propone impuestos en escala flexible a partir de 1979 para los grandes consumidores de petróleo y gas natural; de esta nueva tributación se eximiráa a los fabricantes de fertilizantes y a los que secan productos agricolas que tienen que usar gas. Como las plantas de energía eléctrica, para reacondicionarse al uso del carbón, no estarán sujetas a las nuevas contribuciones hasta 1983.

Mirando hacia el futuro, aun con el retorno al carbón subsiste el déficit energético norteamericano. Mirando al futuro, Estados Unidos dice sí a la energía nuclear, pero no a la economía del plutonio.

Si con respecto al retorno al carbón, el Plan Carter mira al pasado, el Presidente mira también al futuro ya que aun con las metas de conversión. al carbón, subsiste un déficit entre la energía que el país necesita y la energía que puecle producir e importar.

Por tanto, "como último recurso", el país debe "seguir utilizando crecientes cantidades de energia nuclear". 
Se trata de una materia en que el Presidente tienc un pensamiento particularmente preciso, ya que él mismo es ingeniero nuclear y' un aspecto fundamental de su politica exterior se ha diseñado en este campo; el 7 de abril, Carter "anunció que EE. UU. diferirá indefinidamente el reprocesamiento y reciclaje comercial del plutonio asi como también el uso comercial del reactor autogenerador cle plutonio". ${ }^{10}$

Anteriomente los planes de la Comisión de Energía Atómica contemplaban Ia entrada de los Estados Uniclos en la llamada "economía plutonio" en las proximidades del año 2000, épocia en que empezaría el uso masivo de reactores autogeneradores que queman plutonio en lugar de uranio y que tienen la "mágica" característica cle producir más combustible del que consumen; la economía del plutonio aparecía por tanto, teóricamente, como una economia con abastecimiento limitado de energía. Sin embargo, el altísimo poder tóxico clel plutonio, la afirmación de un premio Nobel de que su uso podría llevar a un envenenamiento total del planeta, las clificultades de su manipúlación técnica, el peligro de que pequeñas cantidades del mismo pudieran ser sustraidas para fabricar bombas atómicas, incluso por grupos terroristas o de delincuentes comunes, y las campañas antiplutonio de los protectores del medio ambiente, han configuraclo un complejo cuadro de causas adversas a su uso.

Por ello el Plan de Carter dice "no" a la economía del plutonio y" a la autorización de un reactor autogenerador propuesto para la Planta del Río Clinch.

En cambio, el Plan alienta las plantas nucleares convencionales y la producción de uranio enriquecido para plantas de energía nuclear de agua liviana. Actualmente Estados Unidos cuenta con 63 plantas de energía nuclear que producen, aproximadamente, el $30 \%$ de su energia total $y$ ' se han otorgado permisos para construir alrededor de 70 más. "Las existencias nacionales de uranio pueden ser suficientes para este número de plantas, por otros 75 'años".

Como aún la energia nuclear convencional es peligrosa, actualmente el procedimiento para que el Gobierno conceda licencia para una planta, alcanza, a veces, hasta 10 años. Carter propone relormar tales procedimientos, estableciendo criterios objetivos $y^{r}$ razonables para otorgar los permisos (las plantas deben situarse alejadas de zonas sismicas, centros poblados, las normas de seguridad deben ser más estrictas, los depósitos para el combustible gastado deben ser más adecuados, etc.) sobre todo uniformando los diseños de manera que las

10 Robert D. Thorne, Acting Assistant Administrator for Nuclear Encrgy, Energy' Research and Devclopment Administration. "Nuclear Energy Policy Statement", Washington, D. C., fotocopia del original, April 21, 1977, p. 5. 
plantas que se ajusten a discños ya aprobados puedan obtener la licencia con mayor rapidez.

Estados Unidos también dice sí a los recursos permanentemente renovables como la energía solar.

Si el Plan es cautelosamente restrictivo con. respecto a la energía nuclear aún convencional, en cambio es decididamente positivo en materia de aprovechamiento tecnológico de los necursos energéticos renovables como la energía solar.

...

$Y$ con rasón. En efecto, si el sol es desde el punto de vista técnico una gran planta termonuclear (o sea que opera por fusión nuclear), y lejos de ser contaminante, es benéfico, epor qué no aprovechar su energia?

En 1968, un destacado especialista norteamericano escribía que el nonto de energía solar: que cae sobre Estados Unidos es miles de veces mayor que la energia total que consume la nación. El problema es "captarla" ya que está difusamente distribuidla y en un dia claro, al mediodia, la radiación solar que cae sobre un metro cuadrado de superficie es casi un kilowatio. ${ }^{11}$

Carter afirmó ante el Congreso que, ahora, "gran parte de la tecnología está ya disponible". "El calentamiento del agua por medios solares y los calentadores especiales ya están listos para su comercialización. Todo lo que se necesita es un cierto incentivo para inciar la ampliación de un gran mercado". Para alcanzar este objetivo, el Plan propone la adopción de un orédito (o deducción) tributario gradualmente descendente, que entraria en vigor de inmediato hasta 1984, para los que compren equipos aprobados de calentamiento solar. "Inicialmente seria el $40 \%$ de los primeros 1.000 clólares y el $25 \%$ de los siguientes 400 dólares invertidos".

A través de tales medidas, la meta es "utilizar la energia solár en más de un millón y medio de viviendas".

El Plan del Presidente propicia igualmente el desarrollo de lá energía geotermal con respecto a la cual "se puede garantizar una creciente producción al proporcionar los mismos incentivos tributarios como los que se otorgan para las operaciones de perforación de pozos de petróleo y gas".

11 Charles A. Scarlott, Energia, en varios autores, Hacia el año 201 S (Buenos Aires, Emecé Editores, 1969) p. 175. Teniendo en cuenta que, de aprobarse el plan del Presidente, EE.UU. será el primer país que usará masivamente la cneryia solar, resulta una ironía de la historia la siguicnte afirmación que Scarloth hace en la misma obra: La energla solar está bien adaptada para la producción reducida (unos pocos kilowatios) para uso local. Esto la hace una bucna candidati para calentar, cocinar, bornbear agua, refrigerar y tareas de comunicación en paises subdesarrollados. Los sistemas de energía solar pueden, pues, tornarse signirirativos sólo para los programas de ayuda al exicrior. 
Al tocar el sector energia, base cle cualquier economín, y más aún cle la elel país más industrializado clel mundo acostumbrado a derrocharla, Carter ha tocado los centros nerviosos más sensibles de la nación. Su programa no sólo afecta al estilo de vida norteamericano en aspectos tan profundamente enraizados en la vida diaria como el uso de los grandes automóviles, para no citar sino un ejemplo, sino que atenta contra gigantescos intereses: las corporaciones transnacionales del petróleo, colosos económicos como la General Motors y toda là industria automovilística, los trabajadores de estas fábricas, las empresas eléctricas, las líneas aéreas, la industria química, la industria del.papel, los textiles, el vidrio, etc.

Es una guerra con muchos frentes y las armas de Carter son el inmenso poder del Ejecutivo su prestigio como Presidente recientemente electo, el prestigio de Schlesinger, la mayoría del Partido Demócrata en el Congreso y la comunicación directa del Presiclente con el pueblo, característica del estilo de su gobierno.

Al iniciar este artículo expresamos que los expertos en opinión pública y' el propio Carter esperaban que, al anunciar un plan de esta envergadura y alcance, su popularidad bajaria hasta en un $15 \%{ }^{12}$. Pero el dramático llamado del Presidente en sus discursos ante la nación y el Congreso, ha sido escuchado y su popularidad ha subido ${ }^{13}$. Pero se trata sólo del comienzo de una batalla.

Examinemos algunas reacciones específicas para apreciar las dimensiones del conflicto. El líder de la mayoría demócrata del Senado, Robert Byrd, ha declarado: "esta es una prueba suprema y requiere un. esfuerzo supremo". El Speaker de la Cámara, Tip O’Neill, exprẹsợ: "esta es la batalla más dura que el Congreso haya tenido jamás". Para apreciar el realismo de tales juicios, hay que tener: en cuenta que el plan de Carter afecta profundamente a los grupos de intereses más poderosos que se mueven en tomo a los parlamen-

12 Time, April 25, 1977, p. 155.

1s Esta información, tomada también del número de Time, citado anteriormente, es contradictoria con la información del New York Time de 29 de Abril. 1977, ya que esta mucstra que la popularidad del Presidente habria bajado significativamente después de su discurso a la nación, sobre el plan energético. Sin embargo, la intcrpretación de la encuesta del New York Times resulta compleja ya quo al mismo tiempo señala que la popularidad general de Carter ha crecido. Por csta razón, afirmamos más adelante que, como "la guerra de la encrgia" constituye un proceso dinámico, hay que tomar estos datos con cautela pucs la popularidad de Carter podría subir o bajar según las altcrnativas de esta "gucrra". 
tarios y' que han sido siempre escuchádos con atención y delerencia por senadores y diputados.

Las opiniones favorables y contrarias al programa se mueven dentro tle un gran espectro que va desde los elogios francos hasta las criticas más duras y despectivas. El Gobernador Republicano de Illinois, James Thompson, ha elogiado y' felicitado a Carter por descubrir ma crisis real y por haberla enfrentado. James B. Hunt Jr., Gobernador Demóciata de North Carolina ha expresado que los que no creen en la crisis son sordos y mudos y que el plan. de Carter es el más fundamentado $y$ ' razonable que jamás ha escuchado ${ }^{24}$. En cambio, el Presidente de la General Motors, Thomas Murphy, al referirse a . Jos impuestos a los grandes automóviles, ha dicho que el plan es "uno de los más simplistas, irresponsables y miopes jamás concebido". ${ }^{1 \sigma}$

- Seguramente la General Motors tampoco está muy contenta ya que, modificando la famosa frase de Eisenhower ("todo lo que es bueno para la G. M. es bueno para los Estados Unidos"), Schlesinger ha afirmado con ironía: "todo lo que es bueno para la G. M. no es necesariamente bueno para los Estados Unidos". Henry Ford II, por su parte, dice que los incentivos tributarios a los usuarios de automóviles pequeños no surtirán efeclo, porque nadie querrá comprarlos. ${ }^{10}$

Dos premios Nobel de Economía han terciado en el debate y sus intervenciones han demostrado una vez más cuan dividido se encuentra el mundo de la "ciencia económica" cuando se trata de juygar o evaluar la política concreta de un gobierno, sobre toclo después cle la crisis mundial proucida por el embargo petrolero y la espectacular alza de los precios de este combustible; la polémica entre tan altos especialistas es muy elocuente por cuanto ilustra que dicha crisis sigue subyaciendo "a pesar de haberse superado los problemas puntuales" que desencadenaron el alza del oro negro."

- Apartándose de la opinión de la mayoría de sus colegas que claman por una programación en materia energética, Milton Friedman ha dicho que el plan "es una monstruosidad".

"¿Cómo es posible que EE. UU. hay'a sobrevivido cerca de dos siglos sin una crisis de energía?" - alega Friedman- para continuar: "Hasta hace algunas décadas no había una Comisión Federal de Energía; hasta hace algunos años no habia una Agencia Fecleral de Energía, ninguna ERDA ni ninguna de esas otras alfabeticas agencias que han aparecido últimamente. ¿Cómo fue que pudimos mane-

It Time, May 2, 1977, p. 32 .

25 Time, Api:1 25, p. 15.

16 Time, ibid.

17 Articulo de Newsweck reproducido por El Mercurio, Santiago, Chile, 22 de mayo, 1977, p. 15 . 
jarnos sin la poclerosa ayuda del "hermano mayor" que nos asegurará que la energia era producida por la gente idónea, en la forma correcta y' para los usos apropiatlos?".

Y agrega Friedman: "La interrención del Estado (Big. Brother')' es el problema, no su solución. Nuestras dificultades comenzaron cuando el gobierno comenzó a fijar el precio del gas hace algunas décadas".

"Los propósitos energéticos del Presiclente Carter van parcialnente en la buena dirección cuando hace que algunos precios subari básicamente por motivo de nuevos impuestos. Pero interfiere con la otra hoja de la tijera, la producción. El incentivo por ahorrar energia és el mismo cuando los precios suben, y'a sea que ello se deba a loś ímpuestos o al mercado. Pero el incentivo por producir es claramenté más grande cuando el vendedor obtiene un precio más elevado qúe el que el gobiemo le otorga. Aqui cl Presidente propone sustituir el miercado por la burocracia".

$Y$ finalmente se pregunta Friedman: "Queremos nosotros reatmente, quiere el Presidente Carter realmente, dejar las decisiones sobire producción y clistribución de energia en el mismo tipo de gente que maneja el servicio de correos?".

Por su pance, el p̧rofesor Samuelson tiene una visión diferente sobre la politica de Carter.

"Realmente, de acuerdo a los hechos políticos actuales no hay otra elección. Continuar con las políticas de no hacer nada significaría incrementar la dependencia de fuentes foráneas de energía. Pedir por un rechazo a todos los controles de precios de la energía; de manera que el mercado resuelva el problema de racionar la escase\%, no tiene ninguna posibilidad de ser aceptada por el Congreso de USA o para el pueblo norteamericano".

$Y$ agrega: "Aun si los impuestos no elevaran el precio de los combustibles y electricidad, el grueso de la gente compraría y usaría menos de ellos ya que hay conciencia de los problemas energéticos. Sóla idiotas o grupos especialmente intenlesados podrán seguiv diciendo que la crisis de la energia es lun milo inventado por las grandes compañias petrolcras o los burócratas de Washington". .

Agrega Samuelson que es posible apreciar de hecho que el pueblo norteamericano ha disminuido su consumo indiscriminado de energia. Sin embargo, el público volverá a sus antiguos hábitos y seguirá comprando grandes automóviles, a menos que se eleve paulatinamente el costo de los combustibles como lo propone el plan de Carter.

"Es cierto que el alza de la gasolina incrementará la inflación. Sin embargo, la absorción de algunos miles de millones de dólares del ingreso disponible de los americanos a causa de estos majores costos será un factor deflacionario que reducirá el crecimiento a menos que 
esté compensado por estínulos monetarios o fiscales. En cualquiera de los clos casos habrá problemas, pero al realizar el plan de Carter los problemas serán más manejables que en el caso opuesto".

Incluso algunos miembros del gobierno, como el Secretario del Tesoro, W. Michacl Blumenthal, $y$ Charles Schultze, presidente deI Gonsejo de Asesores Económicos, y' el Director del Presupuesto, Bert Lance, expresaron sus temores de que el impuesto a la gasolina y a los grandes autos, así como las medidas para forzar a la industria a adoptar equipos más eficientes de calefacción y para "convertirse" al uso de] carbón, pueden tener efectos inflacionarios peligrosos. Pero en último término, el Gobierno en su conjunto y el propio Presidente estiman que el Plan sólo agregará un $0,5 \%$ a la tasa de inflacción, alunque otros economistas consideran que el cfecto inflacionario será del,orden del $2 \%$ al $3 \% 18$. Indudablemente estas discusiones internas en el seno del gobicrno scrán aprovechadas por los que favorecen o. atacan el plan, adoptando cada grupo las cifras que convienen más a sus lineas de argumentación.

Kesumiendo, podría decirse que las críticas al plan se concentran en cliversos aspectos: el impuesto contingente a la gasolina, que es eI aspecto más controvertido del plan, sobre todo por sus posibles electos inflacionarios; los fabricantes de autos y todos los demás sectores industriales cuya actitud adversa ya se destacó; los trabajadores de esas mismas inclustrias que temen que las medidas puedan producir desempleo; los que creen que el plan atenta contra las reglas del juego de.un "mercado libre" y los que estiman que Carter ha exagerado lis dimensiones reales de la crisis. Nos referiremos en párrafo aparte, a este úllimo punto por su especial impartancia y significación.

\section{-. ¿ ¿SON REALES LAS DIMENSIONES DE LA CRISIS ENERGÉTICA?}

Es evidente que para que.el Plan de Carter pueda ser aceptado por cl pueblo y aprobado por el Congreso, es preciso que la nación tenga la convicción profunda de que Estados Unidos se enfrenta realmente a una crisis y que ella reviste las caracteristicas dramáticas clescritas por el Presidente. En esta convicción, en esta atmósfera de psicología social, descansa todo el plan, y si ella no se logra crear, el fundamento nirismo cle todo el programa se desmoronaria ante los cmbates de los vientos polílicos adversos como una casa edilicada sobre la arena. Si

1s Time, ibide. 
el pais no adquiere la certidumbre de que se enfrenta verdaderamentë a una inminente "catástrofe nacional", no se necesita ser profeta pard predecir que el Congreso no lo aprobará o lo mutilará en aspectos esenciales de sus complejos componentes.

El primer punto que hay que destaca: al respecto es que el aumento de la popularidad de Carter después de sus discursos, indica una recepción favorable en la opinión pública. Una encuesta hecha poi la revista $T$ me a lo largo del pais revela que salvo unos pocos cínicos que insisten en que el plan es el producto de una conspiración siniestra entre el gobierno y los grandes del petróleo para hacer subir los precios y esquilmar a los ciudadanos, la mayor parte del país, en todos los sectores politicos y sociales, ha aplaudiclo al Presidente por pedix a Ja nación que confronte las penosas verdades sobre la energía.".1. .

Sin embargo, hay que tomar esta primera reacción como un dato provisorio, ya que ella podría cambiar a lo largo del clilatado debate nacional que el Gobierno y la mayoría demócrata del Congreso tendrán que enfrentar hasta conseguir la aprobación final de la legislación propuesta. 20

Sobre todo, nuevos datos proporcionados a la opinión pública, influirán sin duda en la gran cliscusión.

Sobre este particular es preciso destacar que las conclusiones del informe de la CIA sobre el futuro del mercado del petróleo aparecen contradichas por un. informe reciente de las Naciones Unidas y por un estudio de la OECD.

¿Podrán destruir estas contradicciones el fundamento psicológicosocial que requiere el Plan de Carter para crear un clima de opiniợn que sca "el equivalente moral de una guerra"?

Casi al mismo tiempo que el Presiclente terminaba de anunciar su programa, surgieron los críticos alegando que Estados Unidos y el mundo tenian más petróleo que lo que pensaba Carter. Estos críticos, que no dieron dato aiguno para fundar su opinión, se vieron fortalecidos por un informe técnico de las Naciones Unidas, preparado por un sy'mposium internacional de expertos en petróleo, y que se hizo público la última semana de abril. El estudio es optimista; expresa que la oferta mundial de peróleo y gas natural "estaría dispo: nible, aunque a un costo substancialmente mayor, no sólo para.las próximas dos o tres décaclas, sino nuy probablemente durante. ę periodo de transición hacia el uso de fuentes de cnergía renorable aunque el tiempo de transición durara cien años o más"-n1. El fundàmento de los expertos es que los altos precios del petrólco estimularán

1) Time, May 2, 197\%, p. 32.

20 Ver cita 13.

21 Informe citado por Time, May 9, 1977, p. 34. 
la exploración en áreas remotas, hasta ahora no explotadas perio.que son potencialmente prometedoras como el lecho marino y los casquetes de hielo prolar.:

Algo similar, aunque no tan drástico, sucede con el estudio de la OECD cuyas estimaciones se contraponen con los cálculos del informe de la CIA.

Sin entrar a un análisis detenido de estas contradicciones de los "expertos", basta afirmar que cualquiera que haya estudiado, aunque sea superficialmente, el problema de las reservas mundiales de petróleo y' gas natural, sabe que todos los cálculos son profundamente cuestionables y que en realidad nadie conoce a ciencia cierta, cual, es Ia verdadera situación. En este campo, como en todos los otros, cualquier dogmatismo es acientífico. Sheldon Lambert, gerente de ecoṇomía energética y proyecciones de la Shell, ha terciado en el clebate, resumiendo muy bien el problema: "Cualquiera que diga que conoce exactamente cuales son las reservas y cuando vamos a quedar șin gas y $\sin$ petróleo, es, o bien un ingenuo o un estúpido".." $\therefore$

Esta incertidumbre sobre las dimensiones reales de la crisis favorece en último término a Carter, porque ningún gobemante responsable, ante informes contradictorios sobre materias que afectan gravemente a la seguridad nacional y al porvenir del país como superpolencia, podría entregarse a un optimismo fácil sobre desarrollos futuros sujetos a múltiples imponderables. El papel de un gobernante, en una situación semejante, es optar por la cautela, por los cálculos menos promisorios, para defender asi los intereses vitales de la nación. Esta opinión es también la de poderosos órganos de la prensá norteamericana.

GRUPOS ECONÓMICOS QUE GANAN Y PIERINN CON EL PLAN

Hemos identificado anteriormente los grupos y sectores industriáles que pierden o se ven amenazados por el plan. Existen también ótros a los cuales el programa favorece en mayor o menos medida. Todos estos grupos de presión moverán sus influencias ante el Congresso cn sentido adverso o positivo para que los proyectos de la nueva ligisJación sean rechazados o aprobados.

¿Cuáles son los sectores favorecidos? ¿Cuáles serán los "ganàdores" si el plan se aprueba? 
En primer lugar todo el sector industrial de las empresas al: aislamiento térmico, especialmente los fabricantes de fibras de vidrio (Eiberglass) que han visto aumentar sus ventas desde el embargo petrolero clel 73 . cuando empexó a surgir la conciencia de la crisis energética. La Asociación Nacional de contratistas de estas empresas estima que con los incentivos tributarios del plan, la demanda a uimentará ell un $20 \%$ especialmente en las viviendas. Los tres grancles del sector son al Owens-Carming, la Johns-Manville y' la Certain-Teed $=$.

Las 2ndzistrias del qoctar energia solar, fabricantes de unidades de calentamiento y enfriamiento, figuran, igualmente, en lugar destacado. William Matlock, presidente de la empresa "Sistemas de energía' solar" afirma que si el Congreso aprueba las medidas tributarias de Carter, la meta de 2,5 millones de viviendas calefaccionadas y réfrigeradas por esta técnica, sería alcanzada antes de 1980 y no en 1985 como el presidente ha previsto.

Lo mismo sucede con los productores de carbón ya que los objetivos de Carter exigen aumentar la producción de 665 millones de toneladas anuales a 1.100 millones hacia 1985.

Los ferrocarriles que transportan carbón se encontrarían también ante ganancias inesperadas. Se espera que sc abran. 100 nuevas minasi a lo largo de las rutas en los próximos cinco años, lo que representa un aumento del $50 \%$. del actual rolumen ransportado. Como ello exigirá un aumento de los equipos ferroviarios, los fabricantes respectivos aumentarán sus utilidades.

Los fabricantes de equipos para el control de la polución ven también en el plan un promisorio horizonte ya que mientras más carbón se consuma en las industrias y en las empresas de energia, más equipos anticontaminantes serán necesarios. Algunos de ellos gozan de una amplia gravitación en el mundo financiero; basta señalar el caso de Babcock y Wilson que Wall Street se ha propuesto controlar financieramente debido a sus jugosas utilidades.

La industria de aluminio es también una ganadora porque este méal se usa en las empresas de energía solar, en la construcción para aumentar el aislamiento de pucrtas y ventanas $y^{\prime}$ tendrá que usarse crecientemente en la industria automovilística (se calcula que la clemanda se duplicarai hacia 1982) para disminuir el peso cle los autos y para reconvertir la inclustria a lá fábricación de moclelos más pequeños, ahorradores de gasolina.

Los fabricantes de equipos que ahortan energía constituyen otro

24 Lit información, básica sobre "los sectores industriales ganadores" está extraida de la prensa norteamericana, especíalmente dicl Time, May 9, 1977, pp. $36-37$. 
de los sectores ganadores. Desde luego se encuentran aquí Jos sistemạs de "cogeneración" que se emplean ampliamente en. Alemania Federal y que Estados Unidos como se dijo, utiliza muy poco. La Termo Electron of Waltham ubicada en Massachusetts se encuentra lista para ampliar sus actividacles si el Plan se aprueba. La inmensa cadena de venta de hamburguesas, la.Mac Donald's Corporation, distribuida en todas las carreteras y autopistas de la nación, ante el.costo creciente de la electricidad está y'a ensayando un nuevo.motor. eléctrico que reducirá su consumo en $20 \%$; esta innovación tecnológica tendria múltiples aplicaciones, en otros sectores, ya quẹ podria adaptarse fácilmente a millones de motores que actualmente se utilizan en diversas activiclacies:

Los "ganadores" entusiasmados ante el Plan de Carter, están formando y'a sus líneas tde batalla para enfrentarse con los grupos de presión de los "percleclores" ante el Congreso y los parlamentarios y'a se están viendo asediados por cartas, telegramas y maniobras más sutiles ide los poderosos intereses en juego.

Hay otro gran centro de poder, Wall Street, que también es extremadamente sensible a las repercusiones del Plan, porque éste crea incertidumbres entre los inversionistas. Por ello el promedio del Indice general de la Dow Jones ha bajado 28 puntos en las tres primeras ruedas de la Bolsa que siguieron al Mensaje de Carter al Congreso. Pero hay una tendencia clara: las acciones de las emprésas "ganadoras" están subiendo mientras que están. bajando las de las industrias "perdedoras", -lineas aéreas, industria automovilistica, 'compañías petroleras, etc.

Las innovaciones tecnológicas se cuentan por miles en los Estados Unidos y las oficinas del Gobierno encargadas de otorgar las correspondientes licencias se ven asediadas por los inventores, algunos de ellos no siempre muy equilibrados, pero convencidos todos de la bonclad $y^{\prime}$ utilidacl de sus invenciones.

Por supuesto aquellos que trabajan para grandes empresas no tienen que sufrir las dificultades de una larga, tediosa y casi siempre irritante tramitación, ya que las companias respectivas los respaldan.

El Bureau of Standards, oficina gubernamental encargada de eraluar las invenciones, ha recibido 4.278 solicitudes en el sólo campo de los equipos o instrumentos dedicados a ahorrar energia. De este número impresionante, únicamente 22 han sido recomendados para apoyo financiero federal y entre ellos se encuentra Albert 'Cíonka, de 77 años, modesto jubilado, que ha inventado un carburador de automóvil que, de acuerdo con las estimaciones de los técnicos federaless, podria ahorrar millones 'de galones de gasolina al año si. fừera 
comercializado. Se trata de un carburador que opera una mezcla más refinada de aire $y^{\prime}$ petróleo que los modelos actuales y que podría ahorrar $29 \%$ de combustible.

El infortunado Csonka se ha encontrado con la resistencia de la Administración, de Investigación y Desarrollo de la Energía (AIDE) que le pide datos y más datos sobre como comercializará su invento si es puesto en producción. Ha escrito ya montañas de papeles para la burocracia, pero los grandes fabricantes de automóviles han mostrado hasta ahora poco entusiasmo, sencillamente porque no desean pagar las "royalties" correspondientes a un inventor independiente; sólo la Chrysler y' la Ford han demostrado cierto interés que hasta ahora en nada se ha traducido.

Completamente frustrado, Cisonka declaró recientemente: "Quiero decirles a la AIDE, al señor Schlesinger y' al señor Carter: Señores, Uds., han perdido ya medio año. Ya debiéramos tener un carburador que pueda ser colocado en un auto" 25 .

Hemos traídos a colación el caso Csonka por su valor ilustrativo, ya que si el Plan es aprobado, los inventores pulularán en las oficinas del gobiemo $y$, ciertamente, los grandes fabricantes de automóriles, mientras luchan por derrotar al presidente, deben estarse preparando para afrontar el desafío.

"Explotar la línea de menor resistencia", "ajustar sus medios a sus fines", "escoger el camino o línea menos esperado", "asegurar que tanto el plan y' sus disposiciones son flexibles y' adaptables a las circunstancias"; estas son algunas de las recomendaciones que el famoso estratega inglés B. H. Liddell Hart escribió para todos aquellos -militares, políticos, empresarios, ejecutivos en. general- que desean dar una batalla en cualquier campo de actividad ${ }^{20}$.

Ignoramos si Carter $y^{r}$ sus asesores han leído al famoso militax inglés inspirador de generales y estrategas de la Segunda Guerra Mundial. Es muy probable que así sea. Pero lo que importa es que la estrategia de Carter para asegurar el triunfo de su plan parece ajustarse a las recomendaciones de Liddell Hart.

En primer término, parece evidente, hasta ahora, que la opinión pública es más receptiva al plan Carter que el Congreso, sometido a mil presiones. Por tanto, el recurso directo al pueblo constituye "la línea de menor resistencia" en términos estratégicos.

Como el programa del presidente envuelve en el fondo cambios importantes en el estilo de vida norteamericano, que afectan al hombre común, hay que convencer al ciudadano medio que el proyecto del Ejecutivo debe ser aprobado. Es el conjunto de los "hom-

At The Economist, 23.29 April, p. 44.

20 B. H. Liddell Hart (Ncw York, Frederick A. Praeger, 1954), pp. 34\$-49. 
bres comunes" el ámbito "ssicológico clonde debe prender el requerimiento de Carter del "equivalente moral de una guerra". Esos "hombres comunes" son los vehículos para "ajustar los medios a los fines", la segunda proposición del capitán Hart.

No ha sido frecuente que los presidentes norteamericanos recurran masivamente a la opinión pública para forzar al Congreso a adoptar una compleja decisión con múltiples implicacion.es. Ello sería "escoger el camino menos esperado" -tercera proposición de Hart- para obtener que el Congreso apruebe una legislación de enorme trascendencia, aun a la mayoria democráta.

Por ello, es "preciso asegurar que el plan y' las disposiciones (de la batalla) sean flexibles $y$ adaptables a las circunstancias" - cuarta recomendación de Hart- a fin de prever y estar preparado para un próximo paso si se tiene éxito parcial, lo cual es lo más frecuente en los conflictos militares o políticos. Por esta razón las disposiciones del plan estratégico deben permitir una adaptación de las líneas de batalla en el más corto tiempo posible.

¿Por qué decimos que la estrategia de Carter parece adaptarse a estas normas? Sencillamente porque el presidente y sus asesores están pensando que la única forma de obtener que el programa atraviese el Rubicón del Congreso es generando un apoyo popular de tal envergadura que sea capaz de barrer con los grandes tentáculos de los gigantescos intereses creados que tratan de ahogar a la mayoría demócrata.

Por estas razones, el Ejecutivo está planeando una campaña de "venta" del plan energético a la opinión pública que va mucho mús allá de lo usual en estos casos. Uno de sus elementos es confeccionar un, registro de todos aquellos funcionarios de la Administración que podrían explicar el programa, no sólo en las familiares entrevistas en la televisión como "Face the Nation", "Meet the Press" "Issues and Answers", sino también en los programas popularcs de T.V., de famosos animadores como Johnny Carson, Mery Griflin y otros. El segundo aspecto de la campaña es que todos los miembros del gabinete $y$ los funcionarios superiores cuentan ya con "paquetes" de información, especialmente preparados para "vender" el plan, en cualquier discurso o charla que tengan que dar, aunque verse sobre otra materia, ante cualquier auditorio en cualquier parte del país. Por supuesto, el presidente hará lo mismo. El tercer componente es que el Comité Nacional del Partido Demócrata $y^{\prime}$ los funcionarios locales están. formando equipos de trabajo (task forces) para "vender" la política de la Casa Blanca a los grupos cívicos. El quinto elemento es que el gobierno está planeando introducir los puntos de su política en la Conferencia Nacional 
sobre Educación en Energía que se reunirá este mes de junio y si lugia tal objetivo, tales elementos podrían ser introducidos en las escuelas del país en el próximo otoño. La sexta línea de ataque es contrstar servicios con la universidacles para realizar seminarios sobre energía. Otra línea de combate es contratar avisos comerciales en la T.V. sobre ahorro de energía

Los Republicanos, por su parte, están tratando de diseñar un plan alternativo de energía, pero hasta ahora no han podido ponerse de acuerdo en un programa coherente. Sin embargo, ya están plancando recurrir también a la T.V. para atacar uno u otro puntó d'el programa presiclencial.

Los ejecutivos de las grandes empresas "perdedoras" están tambiến adoptando sus estrategias y tácticas, que se llevarán a cabo en público, en un plano "elevado", "digno" y "patriótico", alabando a Carter por enfrentar un problema urgente, mientras en privado lo atacarán y sobre todo formarán sus líneas de batalla para atacar "dignamente" cuando empiece la discusión en el Congreso y "ferozmente" a través de sus poderosos medios. Los ejecutivos comprenden bien la situación: saben que si enfrentan directamente a Carter en público serán simplemente arrollados por la popularidad del presidente y por la inniediata percepción clel público de que defienden principalmente sus intereses.

No obsiante la sagacidad de la campaña estratégica de Carter y el peso de su inmenso poder, la batalla ante la opinión pública no será fácil pues el "hombre común", que ya estál escribiendo a sus parlamentarios, apoya el plan en general, pero manifiesta poco entúsiasmo o no está de acuerdo con medidas especificas. Pero éste no es, al parecer, el obstáculo mayor: la gran dificultad es el tipo de relaciones de Carter con el Congreso.

Como señala acertadamente el Economitist, simplèmente recogiendo la opinión prevaleciente en Washington, durante los primeros cien clias de su administración, Carter ha gastado una considerable cantidacl cle tiempo para explorar y abrir nuevas líneas de comunicación con el "hombre común", cumpliendo así una de las promesas de su campaña; en cambio, no ha sucedido lo mismo con respecto al Congreso. Aunque hasta ahora no se ha enfrentado con el Parlamento, la sola experiencia importante de su relación con los legisladores no es precisamente brillante. En efecto, cuando el presidente propuso una deducción tributaria (no tiene ninguna relación con el plan energético) de cstímulo económico, a pesar de que la medida ya había sido aprobáda por la Ciimara y que

2i Time, ibid. 
formaba parte de un acuerdo con los líderes democrátas del Congreso, ante el comienzo de la oposición en el Senado, Carter la retiró, porque uno de los miembros de su administración, en conlua de la opinión de Charles Schulize (presidente del Consejo de Asesores Económicos), lo convenció de que el proyecto no era conveniente ${ }^{28}$. El retiro del proyecto fue anunciado pọ la Casa Blanca antes de que los senadores democrátas hubieran sido informados; fue un incidente que seguramente los senadores resincieron, aunque públicamente no lo mani[estaron. Sin embargo, cuando Carter ha juzgalo que algo es vital, ha hecho valer todo el peso de su influencia y ha ganacio: así ocurrió con el nombramiento de Paul Warinke como negociador de la linitación de armamentos estratégicos cọn los soviéticos (SALT). Este es precisamente el caso del plan ener. gético, que constituye la gran prueba de su relación con el Congreso.

Cabe señalar que el estilo de Carter aparece hasta ahora desfavorable a discutir previamente con los lideres del Partido Demóciata las medidas legislativas o los pasos que piensa adoptar; por temperamento, Schlesinger también participa cle esta actitud.

La trayectoria de la nueva administración en esta muteria plantea un interrogante para el exito del plan energético en el parlamenio. La estrategia de Carter de recurrir a la opinión pública para que e] Congreso se sienta "abrumado" por la presión de sus elector"cs, tiene también sus riesgos porque puede enajenarse la simpatía de un parlámento que ha ido ganando poderes frente al Ejecutivo cuando lat presidencia se debilitó por la crisis de Watergate; sin embargo, el parlamento actual es nuevo y el presidente tiene una amplia mayo. ria que, aunque pueda "resentirse" por algunas actuaciones de Carter, tiene también que cuidar el futuro del Partido Demócrata, inlimamente Jigado al exito del Jefe del Ejecutivo.

En resumen, "la guerra de la energia" en el Congreso se presenta como extremadamente compleja, también desde el punto de vișta de la relación cle los poderes colegisladores. Razón de sobra para que Carter $y$ sus asesores planifiquen la relación con el Congreso en la misma forma cuicladosa en que han modelado su campaña de opinión pública, manteniendo un plan de batalla "flexible y' adaptabic a las circunstancias", en Ja batalla legislativa el presidente podría sacar repentinamente una carta de triunfo si, por ejemplo, el inpuesto a la gasolina (repetimos que es el aspecto mís controvertido del plan) estuvicra en peligro de ser rechazado; amenazar con. inplantar o simplenente decretar el racionamiento de gasolina, para

29 The Economist, $29-29$ April, p. 43. 
lo cual dispone de facultades legales y que, por tanto, puede hacer por una simple orden ejecutiva.

LA INCOCGNTTA DE LA PERSONALIDAD DE CAKTER EN LA CUERRA DE LA ENERCIA

Estaria Carter dispuesto a llegar al cxiremo de la implantación del racionamiento, si la "guerra de la energía" lo enfrenta a una siluación dramática para el interés nacional tal como él lo juzga?

No hay duda de que un lider como De Gaulle, colocado en una situación semejante, lo habria hecho. Porque su personalidad se inclinaba a los gestos históricos, grandiosos y espectaculares. Pero la personaliadd de Carter está muy' lejos de ese tipo de liderargo, aunque no pociria afirmarse que necesariamente lo excluya.

La verdad es que su personalidad es en extremo compleja: religioso militante, ingeniero nuclear, empresario exiloso como administraclor de los negocios de su familia, gobernador eliciente de un estado "subciesarrollado" como Georgia, frio, metóclico e incansable en su trabajo, strgió practicamente de la oscuridacl política al caror con mayor poder del mundo; laborioso y eficiente hasta el extremo, la sido considerado como el presidente más activista en los primeros meses dic su mandalo, que ha tenido Estados Unidos descle la Segunda Guerra Mundial. En los escasos primeros meses de su manclato ha producido un shock en la comunidacl internacional con una serie de audaces iniciativas; momalista por convicción profunda, se ha cuidaclo de aparecer como prigmálico en la reciente reunión en Ia cima de Londres con los grandes países industrializaclos; ordenaclo, como buen ingenicro, estuclió previamente las biogralias de los lideres dei mundo con los cuales tenia que negociar. Casi sin experiencia intemacional, logró impresionax a los licleres cle Europa y Japón, colocar a la delensiva a la Unión Soviética con su politica. de derechos humanos, mientras cleterioraba las relaciones con países claves tan dispares como Alemania Federal (ahora restauradas clespués de la reunión en la cima) y Brasil. A diferencia de muchos ingenieros, prefiere una visión amplia $y^{\prime}$ sintética de los pro. blemas, pero a semejanza de ellos, le gusta también conocer los detallles. Cultivitclor exitoso de mani, ha clespojado at la Casa Blanca de muchas de sus pompas $y$ ceremonias $y$ ha implantado los "blue jeans" y' desterrado la corbata de su indumentaria cle trabajo y de la de sus asesores. Hace, a, veces, recomendaciones evangélicas para 
pasar de inmediato a analizar complejos problemas de tecnología nuclear. Parece cntenderse tan bien con Anclrew Youngr, su poco "diplomático" embajador ante la N.U., como con el preciso y correcto James Schlesinger.

En suma, una personalidad multifacética y desconcertante que impicle prever su comportamiento en la primera gran prueba nacional de sus reales 'clotes de gobernante.

\section{LAS IMPLICACIONES MUNDLALES DEL MIAN DE CAR'THR}

Por muchos conceptos el plan de Carter tenchría implicaciones mundiales si es aprobatlo en sus aspectos esenciales. En primer lugar, y obviamente, por lat gravitación planetaria de la economia norteamericana; políticamente porque fortalecerá al pais en su abastecimiento energético y le permitirai en[rentar mejor los clesalfíos futuros de su politicat internacional.

En scorundo témino el plan tendria un efecto de demostración en muchos paises que - mutatis mutanclis- scguirian su cjempio, ya que la adopción cle una politica energética previsora se pondria de moda con tocias las consecirencias psicológicats de la imitación.

En tercer lugar, las nuevas tecnologías cuyo desarrollo el plan requiere, influirian también en muchos países. Asî cuando la industria clcl automóvil creara modelos ahorraclores de energia, europeos y japonceses deberian innovar tumbién para no perder mercados. Las innoraciones en los artefactos electrodomésticos y en los sistemas cle aislamiento térmico conducirian a la obsolescencia de los antiguos modelos. lil clesarrollo de las técnicas cle energía solar podria ser aprovechado en paises como Chile. Podrian asi cnumerarse variaclos efectos en casi caclat uno de los aspectos que cubre el pian.

Cualquiera que sea la suerte que el programa corra en el Congteso, fuern de los Listados Unidos, desdle el punto de vistit clel "hombre común" no norteamericano, políticamente las opiniones aparecen claramente diviclicas. Aqquellos que tienen convícciones democráticas se admiran al contemplar cómo los diversos mecanismos de una gran democracia se preparan para ponerse en funcionamiento y plena acción en la guerra de la energia, clurante la cliscusión parlamentaria. En cambio, los defensores de los regimenes autoritarios se asombran al presenciar el "cspecticulo" de un Congreso sometido a innumerables presiones $y$ de un Ejeculivo que liene que gastar un enorme esfuer\%o para convencer a un parlamento con majoría de 
su propio partido. En cambio - piensan ellos- en un régimen alutoritario, un plan semejante, vital para la seguridald nacional, se aprobaria por un simple decreto presidencial.

Con respecto a estos últimos, cabría señalar que si no fucra por Jos mecanismos de la democracia, el Plan Carter no existiria pues su autor continuaría siendo un cxiloso cultivador de mani en Plains, Georgial. 